\title{
Application and Performance Test of High Temperature Filter Media Used on Bag-house duster
}

\author{
CHEN Chun-xia \\ Yancheng Institute of Industry Technology \\ Department of Textile Engineering \\ Yancheng, Jiang su 224005 \\ E-mail: chx9941@126.com
}

\begin{abstract}
In this article physical and chemical testing index and filtration effect index are explained in detail. Tested the filtration effect of the GLASS filter media、PPS media、 METAMAX, and FMS filter media by use of German AFC-131 filter media test rig. And Then tested their breaking strength, permeability、temperature characteristics and the like. Compared with the standards, Performance comparison of various specifications of filter cloth were done, the optimized designed specifications of the filter cloth were worked out. Finally, analysised the application prospect of the high temperature filter media.
\end{abstract}

Key words- high temperature filter media; application; filtration effect; testing;

\section{PREFACE}

A large number of high-temperature gas containing dust will be produced in the chemical, petroleum, metallurgy, electric power, cement and other industrial production, such as flue gas from the cement industry of kiln head and kiln tail, blast furnace gas from the iron and steel industry, boiler flue gas in coal-fired thermal power plant, waste incineration flue gas Etc., the main part of the gas dust removal is high temperature filter material, which can remove dust effectively, and can capture the dust of different properties, the effective improvement of the environment is reached ultimately.

Currently, there are many kinds of filter media on the market, the performance and usage differ each. Methods of classification are also different. According to the material temperature resistance characteristics they can be divided into extreme temperature filter material、 high temperature filter material、medium temperature filter and normal temperature filter.

\section{TESTING INDEX FOR BAG HOUSE DUSTER} index:

1.1 The conventional physical and chemical testing

According to the GB T 6719-2009 specifications for bag house and HJT 324-2006 specifications for environmental protection product. Testing index for Filtering Media Used on Bag-house duster are as follows:

(1)Breaking strength retention after acid and alkali treatment: Treatment with $60 \% \mathrm{H}_{2} \mathrm{SO}_{4}$ and $40 \% \mathrm{NaOH}$ respectively for 24 hours, then test the breaking strength retention of the original sample and the treated one.
(2)Friction potential: Tested the amount of charge on the filter media after rubbing the nylon fabric by use of fabric friction charged tester, the unit is $\mu \mathrm{C}$ 。

(3)Surface charge density: An index of filter material's electrostatic properties, Rubbing the filer media with the nylon plain weave and tested the amount of charge $\mu \mathrm{C}$, then divided by the friction area, unit is represented by $\mu \mathrm{C} / \mathrm{m}^{2}$.

(4)Temperature resistance: Test the sample's warp and weft strength by use of high -temperature thermostatic test case before and after processing. Then calculate the strength retention rate, the warp and weft length were tested before and after processing, calculate the heat shrinkage rate at last.

(5)spray rating: Testing and grading according to the GB/T 4745-1997 by use of the fabric spray testing instrument with $20{ }^{\circ} \mathrm{C}$ water.

(6)Oleophobic: The sample is cut into $20 \mathrm{~cm} \times 20 \mathrm{~cm}$ and then test the filter's oil repellent grade with the stopwatch.

(7)Air permeability: The media is cut into $50 \mathrm{~cm}^{2}$ size and test the air permeability. by use of digital fabric air permeability apparatus with the proper nozzle under the pressure drop of $200 \mathrm{~Pa}$.

1.2 Testing index for filtration effect

(1)Static dust collection efficiency: The media started from the clean state, continuous dust filter without cleaning, test the filtration efficiency when the dust holding capacity reaches the specified value. Results: static dust collection efficiency $=$ (dust mass of the measured filter)/ (dust mass of the measured filter + dust mass from the high efficiency filter $) \times 100$.

(2)Operational dust collection efficiency: The filtration efficiency under the condition of dust cleaning according to the provisions of the system, at the same time, the filter material is filtering dust, \%。

(3)Resistance coefficient: The system resistance of the bag-house duster consists of three parts that are structural resistance, dust cleaning filter resistance and the resistance from the dust layer attached to filter. In dust removal system, resistance from the filter cloth accounts for a large part of the whole system, it include the resistance of the cloth itself and the resistance produced from the dust layer. In this paper filter resistance coefficient tested under the specified filter velocity is the ratio of clean filter's resistance and the filter rate, the unit 
is $\mathrm{Pa} \cdot \mathrm{min} / \mathrm{m}$.

(4)Residual pressure drop: This is the filter's pressure after cleaning according to the stipulated conditions while the filter pressure up to the specified value and the filtering speed is fixed, the unit is $\mathrm{Pa}$.

\section{DUST REMOVAL EFFECT TESTING AND ANALYSIS OF SEVERAL HIGH TEMPERATURE FILTER MEDIA}

The experimental instrument: German AFC-131 filter media test rig

The experimental environment: temperature: $25 \pm 2^{\circ} \mathrm{C}$

humidity: $\quad 50 \pm 10 \%$

Instrument precision: differential pressure 0-2500pa

Experiment dust: $\mathrm{AL}_{2} \mathrm{O}_{3}$

Dust cleaning differential pressure: 1000pa

Filtration velocity: $1 \pm 0.1 \mathrm{~m} / \mathrm{min}$

Dust concentration: $5 \pm 0.5 \mathrm{~g} / \mathrm{m}^{3}$

Pulse jet time: $50 \mathrm{~ms}$

Test steps:

\subsection{Resistance coefficient testing:}

(1) Take three $145 \mathrm{~mm}$-diameter circular filter samples, which should be far away from the edge more than $30 \mathrm{~mm}$, and should not be in the same system of warp or weft system.

(2) Determine the filter's windward side, and then put the clean filter on the filter sample clamping fixture.

(3) Open air pump, determine the filter resistance of different filter velocity

(4) Calculate the filer's resistance coefficient

(5) Test three filer samples' resistance coefficient, finally take the average

\subsection{Static dust collection efficiency testing:} first.

(1) Weigh the filter and the high efficient filter paper

(2) Put the clean filter on the filter sample clamping fixture, in order to collect dust high efficiency filter paper should be installed on the right of the filter.

(3) Open air pump, adjust the flow at the speed of $1 \pm 0.1 \mathrm{~m} / \mathrm{min}$.

(4) Starting up dust collector, Control the dust concentration as $5 \pm 0.5 \mathrm{~g} / \mathrm{m}^{3}$, Continuous dust $10 \mathrm{~g}$

(5) After testing, weigh the high efficient filter paper and the filter respectively.

(6) Calculate static dust collection efficiency.

2.3 Operational dust collection efficiency testing:

(1) Weigh the filter and the high efficient filter paper weight first.

(2) Put the clean fabric on the filter sample clamping fixture, in order to collect dust high efficiency filter paper should be installed on the right of the filter.
(3) Open air pump, adjust the flow at the speed of $1 \pm 0.1 \mathrm{~m} / \mathrm{min}$

( 4 ) Start up dust collector, control the dust concentration as $5 \pm 0.5 \mathrm{~g} / \mathrm{m}^{3}$.

(5) Dust cleaning when the pressure drop is $1000 \mathrm{~Pa}$, after repeated 30 times measure the high efficient filter paper's weight gain and the outlet dust concentration.

(6) Ageing treatment: repeated dust cleaning of $5 \mathrm{~S}$ interval during the filtration for 10000 times.

(7) Test media's performance when stable, operated according to step 5, then test the dust amount and the outlet dust concentration.

(8) Record instantaneous resistance value of the whole process.

(9) Calculate operational dust collection efficiency, test three samples' operational dust collection efficiency and then take the average.

Four kinds of domestic high temperature filter materials (17 kinds of specifications) were detected, and the test results are shown in Table 1 and table 2 .

Table 1 listed the data and technical requirements of six kinds of FMS filter, table 2 is the test data for METAMAX of 3 specifications, 4 kinds of PPS filter, 4 kinds of glass filter media, From the above tables we can see that the cloth's weight of unit area and the thickness will obviously affect the media's strength, permeability, resistance coefficient, the dust removal efficiency. The temperature characteristic is mainly affected by the filter material itself. The larger the weight of unit area, the smaller the thickness, the higher the fabric's density will be, the porosity will become small, the dust removal efficiency of the filter cloth is relatively high, good fastness, resistance coefficient become smaller, but will also lead to increased costs, bad permeability. Through the above data and compared with standard we can see among the four kinds of filter media FMS and GLASS filter have good strength. Fabric's air permeability CV value differ greatly, this is directly related to the fiber's porosity and the property and distribution of the fiber. Air permeability $\mathrm{CV}$ values have great difference indicating that the fiber's distribution is very uneven. this will seriously affected the filter material's resistance and filtration effect.

Standard requires that the permeability $\mathrm{CV}$ value should $\leq 8$, compared with the technology requirements of the Standard, the glass media weighted 940 is qualified for all the items. Performance of FMS media weighted 1024 and PPS media weighted 523 are excellent but heat resistance and breaking elongation are not satisfied, so they don't fulfill the general using requirement. 
Table 1 Performance testing of FMS filter media

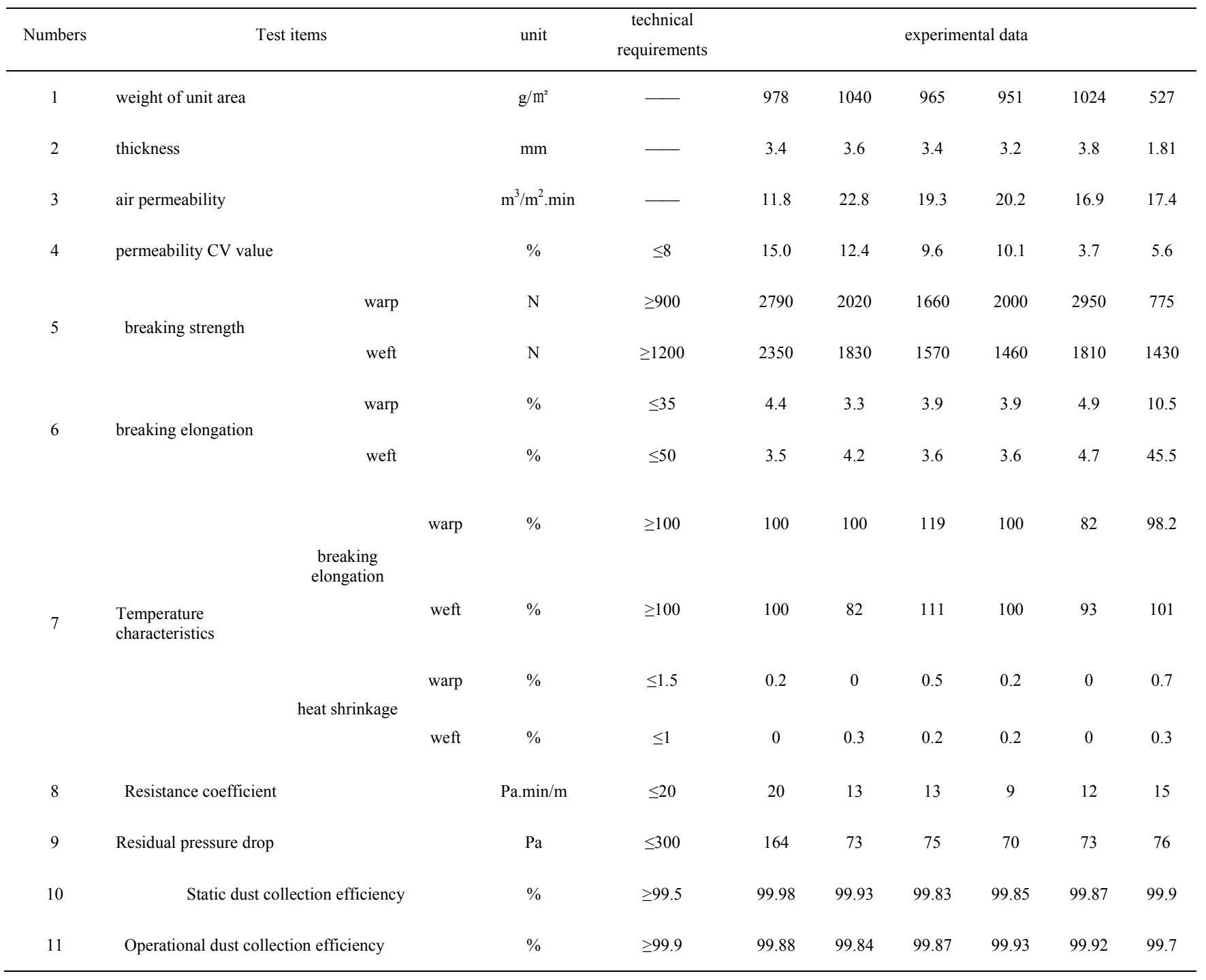


Table 2 Performance testing of METAMAX、PPS and GLASS filter media

\begin{tabular}{|c|c|c|c|c|c|c|c|c|c|c|c|c|c|c|c|}
\hline \multirow{2}{*}{$\begin{array}{c}\text { Numbers } \\
1\end{array}$} & \multirow{2}{*}{$\begin{array}{l}\text { Test items } \\
\text { weight of } \\
\text { unit area }\end{array}$} & \multirow{2}{*}{$\begin{array}{c}\text { unit } \\
\mathrm{g} / \mathrm{m}^{2}\end{array}$} & \multicolumn{2}{|c|}{$\begin{array}{l}\text { technical } \\
\text { requirements }\end{array}$} & \multicolumn{3}{|c|}{ METAMAX } & \multicolumn{4}{|c|}{ PPS } & \multicolumn{4}{|c|}{ GLASS } \\
\hline & & & & & 467 & 503 & 605 & 620 & 512 & 523 & 502 & 940 & 881 & 1110 & 902 \\
\hline 2 & thickness & $\mathrm{mm}$ & & & 2.5 & 2.3 & 2.40 & 2.0 & 2.0 & 2.2 & 2.80 & 3.2 & 3.5 & 4.4 & 3.39 \\
\hline 3 & Air permeability & $\mathrm{m}^{3} / \mathrm{m}^{2} \cdot \min$ & & & 3.6 & 17.0 & 1.7 & 13.2 & 22.9 & 19.6 & 22.1 & 21.2 & 24.7 & 21.0 & 26.9 \\
\hline 4 & $\begin{array}{c}\text { permeability } \mathrm{CV} \\
\text { value }\end{array}$ & $\%$ & & & 17.5 & 6.9 & 13.1 & 7.4 & 10.9 & 6.2 & 12 & 4.6 & 10.1 & 13.2 & 10.7 \\
\hline \multirow{2}{*}{5} & breaking strength & warp N & \multicolumn{2}{|c|}{$\geq 900$} & 908 & 713 & 855 & 702 & 1040 & 910 & 610 & 2120 & 2820 & 1550 & 1530 \\
\hline & & Weft N & \multicolumn{2}{|c|}{$\geq 1200$} & 901 & 752 & 1290 & 1420 & 1200 & 1570 & 1370 & 1910 & 1750 & 1540 & 1660 \\
\hline \multirow{2}{*}{6} & breaking elongation & Warp \% & \multicolumn{2}{|c|}{$\leq 35$} & 12.3 & 15.6 & 18.0 & 103 & 49.2 & 76.3 & 16.5 & 5.4 & 3.7 & 3.6 & 6.6 \\
\hline & & Weft \% & \multicolumn{2}{|c|}{$\leq 50$} & 48.2 & 61.2 & 58 & 47.9 & 58.6 & 41.6 & 56.5 & 4.4 & 3.6 & 3.3 & 7.0 \\
\hline \multirow{4}{*}{7} & \multirow{4}{*}{$\begin{array}{l}\text { Temperature } \\
\text { characteristics }\end{array}$} & \multirow{2}{*}{$\begin{array}{l}\text { breaking } \\
\text { elongation }\end{array}$} & warp & $\geq 100$ & 100 & 110 & 104 & 100 & 100 & 100 & 120 & 100 & 95 & 100 & 90.2 \\
\hline & & & weft & $\geq 100$ & 112 & 100 & 105 & 100 & 87 & 100 & 109 & 100 & 95 & 100 & 81.9 \\
\hline & & & warp & $\leq 1.5$ & 7.4 & 2.9 & 1.2 & 0.8 & 4.3 & 4.6 & 6.2 & 0 & 0 & 0 & 0 \\
\hline & & & weft & $\leq 1$ & 2.4 & 1.5 & 0.5 & 0.2 & 6.4 & 5.4 & 7 & 0 & 0 & 0 & 0 \\
\hline 8 & $\begin{array}{l}\text { Resistance } \\
\text { coefficient }\end{array}$ & Pa.min/m & & & 85 & 12 & 10 & 16 & 10 & 10 & 10 & 8 & 8 & 16 & 10 \\
\hline 9 & $\begin{array}{c}\text { Residual pressure } \\
\text { drop }\end{array}$ & $\mathrm{Pa}$ & & & 480 & 68 & 67 & 71 & 49 & 54 & 41 & 62 & 59 & 125 & 67 \\
\hline 10 & $\begin{array}{l}\text { Static dust } \\
\text { collection } \\
\text { efficiency }\end{array}$ & $\%$ & & & 99.98 & 99.93 & 99.8 & 99.84 & 99.65 & 99.75 & 99.5 & 99.80 & 99.74 & 99.87 & 99.8 \\
\hline 11 & $\begin{array}{l}\text { Operational dust } \\
\text { collection } \\
\text { efficiency }\end{array}$ & $\%$ & & & 99.99 & 99.94 & 99.9 & 99.96 & 99.82 & 99.93 & 99.8 & 99.90 & 99.82 & 99.93 & 99.9 \\
\hline
\end{tabular}

\section{APPLICATION PROSPECT ANALYSIS OF THE HIGH TEMPERATURE FILTER MEDIA}

Review the large and medium-sized cities of our country, they suffer more and more haze weather in recent years, the most representative city is Beijing, people suffer extremely. Haze specifically refers to the inhalable Particulates of 2.5 microns to 10 microns in diameter, which is PM2.5 PM10, these particles come from the automotive, waste incineration, cement, steel, chemical and other industries polluted seriously. So China will become the faster growing country of filtration market all over the world, application of bag-house duster is continuously expanding to meet the demand of various industrial fields, and create a good environment for the survival of the earth. The high temperature filter used for bag-house duster are full of vitality, enterprises should accelerate industrial upgrading and technological upgrading, and improve the product standardization, specialization, and promote the sustainable development of bag filter in our country. In a word, the filter's future development is mainly reflected the following two aspects.
(1)The development of the situation requirements that bag house duster technology should play an increasingly important role in industrial smoke and high temperature industrial dust control. The design of filter cloth Should be based on the actual situation, fully considering the factors of influencing the dust removal effect and the service life and raising the fine particle (PM2.5 PM10)collection efficiency, makes contribution for the improvement of the atmospheric environment.

(2)Working hard to develop composite nonwoven filter material, reduce cost, combined the good qualities of each material, replenish the shortage of the materials, get the development at the aspect of light and low cost.

\section{REFERENCES}

[1]Standardization Administration of the People's Republic of China, GB/T 6719-2009 Specifications for bag house[S], Beijing: Chinese Standard Press, 2009。

[2]CHEN Chun-xia, Analysis of filtration effect of the filter media used for bag-house duster [J], SHANGHAI TEXTILE SCIENCE AND TECHNOLOGY , 2013.4.57-59。 
[3]Research on Extending Service Life of Filter Bag of High-temperature Fiber Glass Bag Filter, 2006。

[4] CAI Wei-long, LUO Xiang-bo, Application Status and Development Trend on Bag - hose Precipitation of Filtering Materials with High Temperature in China[J], CHINA ENVIRONMENTAL PROTECTION INDUSTRY 2011.10. [5] Current Situation and Developing Trends of High Temperature Filter Media, ZHU Ping, SONG Shangjun,

BAI Yaozong, LI Xiaopu, FEI Chuanjun, ZHANG Junrong, ZHANG JianFIBER GLASS [J] 2010, (6)34-38. 